
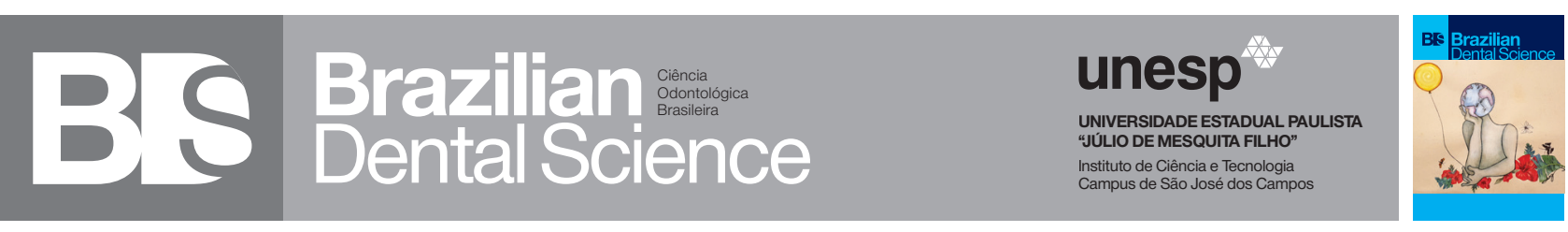

\title{
Dental tooth decay profile in an institutionalized elder population of Northern Portugal
}

\author{
Perfil de cárie dentária numa população idosa institucionalizada do Norte de Portugal \\ Sandra GAVINHA ${ }^{1}$, Paulo MELO $^{2}$, Liliana COSTA ${ }^{1}$, Patrícia MANARTE-MONTEIRO' ${ }^{1}$, Maria Conceição MANSO ${ }^{3}$ \\ 1 - Department of Medical Sciences - Faculty of Health Sciences - University Fernando Pessoa - Porto - Portugal \\ 2 - Faculty of Dental Medicine - University of Porto - Portugal \\ 3 - Faculty of Health Sciences - FP-ENAS - University Fernando Pessoa - Porto - Portugal; REQUIMTE - University of Porto - Portugal
}

\section{ABSTRACT}

Objectives: the purpose of this study was to assess the dental tooth decay profile of an elderly population from Northern Portugal. Material and Methods: this is a descriptive, cross-sectional study where a questionnaire, intended to assess the institutionalized elders oral health condition, was applied with the purpose of quantifying certain oral conditions. Tooth decay was assessed using the DMFT Index for the crown's tooth and the individual radicular caries index (RCIi) for the root's condition assessment. Univariate analysis and multivariable logistical regressions were performed ( $\mathrm{p}<0.05$ ) using the IBM(C) SPSS(C) Statistics vs.19.0. Results: three hundred and seventy-two elderly participants were assessed with an average age of 78.8 years, of which 260 were women $(69.9 \%)$. Of the sample $30.4 \%$ had no literacy and $18.3 \%$ were dependent on their daily oral hygiene care, 30.9\% (95\%CI:26.2\%-35.6\%) were edentulous and $84.9 \%$ (95\%CI:81.3\%-88.5\%) had less than 20 teeth. The average number of teeth was 8.9 ( \pm 8.7) and the DMFT was $25.6( \pm 7.3)$. The RCIi for men was $44.3 \%( \pm 30.4 \%)$ and $39.4 \%( \pm 31.2 \%)$ for women. Using multivariate logistical regression model the outcome RCIi $\geq 20 \%$ was shown to be significantly and positively associated with the use of removable partial dentures (metal partial dentures: OR $=5.348$ (95\% CI: 1.176-24,329; $\mathrm{p}=0.030$ ) as well as with daily tooth brushing (no toothbrushing: OR $=2.802$ (95\% CI: 1.445-5.433); $\mathrm{p}=0.002)$. Conclusion: the prevalence of tooth decay in this elder institutionalized population of Northern Portugal is high, mostly due to bad oral hygiene habits associated to the use of metal removable partial dentures. Institutionalized elderly need protocols tailored to their oral health needs and integrated efforts in the institutions are needed to effectively answer the demands related to the elderly cognitive and motor skills (ageing deterioration) decline of physiological functions.

\section{KEYWORDS}

Elderly; Oral health; Prosthesis; Root caries.

\section{RESUMO}

Objetivos: O objetivo deste estudo foi avaliar o perfil de cárie dentária numa população idosa do norte de Portugal. Material e Métodos: Trata-se de um estudo descritivo, transversal, onde foi aplicado um questionário destinado a avaliar a condição de saúde oral dos idosos institucionalizados, com o objetivo de quantificar determinadas condições orais. A cárie dentária foi avaliada usando o índice CPOD para a coroa do dente e o índice de cárie radicular individual (IRCi) para a avaliação da condição da raiz. Foi realizada análise univariada e regressão logística multivariável $(\mathrm{p}<0,05)$ usando o IBMC SPSS(C) Statistics vs.19.0. Resultados: avaliaram-se 372 idosos, com idade média de 78,8 anos, dos quais 260 eram mulheres (69,9\%). Da amostra, 30,4\% não tinham escolaridade e $18,3 \%$ dependiam de outros para realizar os seus cuidados diários de higiene oral; 30,9\% (IC95\%: 26,2\%$35,6 \%$ ) eram desdentados e 84,9\% (IC95\%: 81,3\%-88,5\%) tinham menos de 20 dentes. O número médio de dentes foi de $8,9( \pm 8,7)$ e o CPOD foi de $25,6( \pm 7,3)$. O ICRi para o género masculino foi de $44,3 \%$ ( $\pm 30,4 \%$ ) e de $39,4 \%$ $( \pm 31,2 \%)$ para o feminino. Usando o modelo de regressão logística multivariada, o resultado ICRi $\geq 20 \%$ mostrou-se significativa e positivamente associado ao uso de próteses parciais removíveis (próteses parciais esqueléticas: $\mathrm{OR}=$ 5,348 (IC95\%: 1,176-24,329; $\mathrm{p}=0$ 0,030), bem como com escovagem diária (sem escovagem: $\mathrm{OR}=2,802$ (IC95\%: 1,445-5,433); $\mathrm{p}=0,002)$. Conclusão: a prevalência de cárie dentária nesta população idosa institucionalizada do Norte de Portugal é alta, principalmente devido à má higiene oral e hábitos associados ao uso de próteses parciais removíveis esqueléticas. Idosos institucionalizados precisam de protocolos adaptados às suas necessidades de saúde oral e esforços integrados nas instituições para atender efetivamente às necessidades relacionadas com o declínio das funções fisiológicas do idoso, cognitivas e motoras (deterioração do envelhecimento).

\section{PALAVRAS-CHAVE}

Idosos; Saúde oral; Prótese; Cárie radicular. 


\section{INTRODUCTION}

A ging is a natural process which is defined as a progressive deterioration of the organism's biological functions, after achieving its height of reproductive capacity. Several genetic studies have been helping us to better understand the variance between individuals, for a more profound understanding of the aging mechanisms as well as of the age related illness' etiology, in order to improve prevention and the therapeutic responses. The biological mechanisms and the aging process are becoming more and more related, the former being inevitable and characterized by the general decline of physiological functions and by the accumulation of deficiencies and diseases which bound the normal functions of the organism $[1,2]$.

The tooth tissues, as those of other body parts, suffer modifications throughout life resulting in pathological, anatomical and physiological changes. Nevertheless, inside the oral cavity, the concept of a dentition's "normal aging" it is not well defined, considering that teeth are subjected to pathological and physiological changes for years, making it often difficult or impossible to understand the role of these two factors on the process [3]. The prevalence of oral diseases increases with age. Tooth loss, permanent presence of active dental caries lesions and a high incidence of periodontal disease are frequently seen as common characteristics of the elderly population's oral health status [4].

Dental caries is one of the most prevailing chronic disease in the whole world, because is cumulative and people are exposed to it throughout life. It can develop in the teeth crowns and/or roots, being related with physical, biological, environmental and behavioural factors, as well as certain associated life styles. Other disease related factors are the presence of a high number of acidogenic bacteria, an inadequate salivary flow, bad oral hygiene habits, insufficient exposure to fluoride, amongst others [5]. At a worldwide perspective, dental caries is considered an important public health problem, which is intrinsically connected, in elderly people, to social action and behavioural factors.

In the aging population several studies have been relating dental caries risk with socioeconomic status, microbiological environment, salivary function, as well as some clinical factors such as the presence of removable dentures and dental plaque $[6,7]$.

The trend of maintaining more natural teeth with age, is another factor contributing to an increase of teeth with exposed roots and consequently more prone to the development caries lesions $[8,9]$. It is known that root decay is more prevalent in this age group than in any other [9]. Dental caries incidence becomes higher in the cement, as well as in the exposed dentin areas, when the root surfaces become exposed, whether it is due to a physiological process or periodontal atrophy. There are other factors associated with age, such as a decrease of saliva quantity, as well as quality, due to pathologic factors or polymedication. Also the lack of oral hygiene, because of the aging deterioration, with the decline of physiological functions, plays a very important role in the process $[10,11]$. As to what concerns elderly eating habits, it seems to be of importance in tooth decay development, as they tend to eat sweeter, soften and sticky foods [7].

However, dental caries is a preventable disease, whether affecting the tooth crown or root, and the strategies for management and prevention of the disease are different for each age. From a practical point of view, it should be understood the importance to intervene in the disease control, starting from the preventive strategies, in this case, much easier to implement than treatment procedures [7]. The high prevalence of dental caries in elderly people is shown by several authors in many European countries ranging from Northern Europe (Norway) that presents DMFT values of 25.4, to Southern Europe countries (Spain), in which the observed DMFT values are of 27.02 and 29.2[1113]. In Japan, 287 elderly over 60 years old were assessed, and $39.0 \%$ of these individuals were 
registered as having one or more carious root and 53.3\% had, at least, one cavity[9]. In Sri Lanka, the root decay prevalence on elderly people was of $89.7 \%$ and the root caries index average (RCI) per individual was of 3.8 [14]. In England, on 462 participants with 65 years old or older, an RCI of $26 \%$ and $46 \%$, respectively, was found in non-institutionalized and in institutionalized elder people [6].

To the best of our knowledge no papers have been produced regarding the dental caries profile of elders in Portugal much less from institutionalized ones. Therefore, the purpose of this study was to assess an institutionalized elderly population from Northern Portugal, as to what concerns its dental tooth decay profile.

\section{MATERIAL AND METHODS}

The study was approved by the Ethics Committee of the University Fernando Pessoa (UFP) and complied with the ethical standards and recommendations laid down in the 1964 Declaration of Helsinki and its later amendments.

\section{Study population}

A descriptive, observational, cross-sectional study was made, through the application of a faceto-face questionnaire and clinical observation (carried out at the UFP-mobile unit, with dental equipment and good lighting conditions) that intended to assess the institutionalized elders concerning their oral health condition by means of quantifying certain oral pathologies, amongst which, dental caries.

The target population should consist of people over sixtyyears old, living in nursing homes. The participants should be independent, that is, capable of performing their own oral hygiene, as well as of answering questions placed to them by the observer, or be partially dependent, only as to what oral hygiene is concerned, that is, to require assistance in some occasions for performing those tasks. The sample was selected using a probabilistic sampling method, considering the 158 elderly nursing homes inside the Oporto district (total of 5855 individuals). Twenty two nursing homes were visited, corresponding to
1046 elder residents. A minimum sample size of 361 was estimated and 372 participants were observed. The participants were enrolled after obtaining written informed consent. From the target population studied, the exclusion criteria were applied to: individuals whom, due to health problems, were not in condition to provide, in a conscious way, permission for being examined; the people under sixty years old. There were also individuals who refused to participate, due to indisposition or justifying themselves with the fact that "they did not have teeth, hence they did not need a Dentist", even after being enlightened by the observer.

The oral cavity observations, as well as the questionnaire, was performed by the first author whom was previously subjected to a calibration done between the former and an external examiner, with the purpose of minimizing the diagnostic variability, that is, the bias from the established criteria. In the assessments, an intraexaminer agreement of $95.0 \%$ was achieved, corresponding to a Kappa of Cohen $(\mathrm{K})$ value of 0.90 .

The adopted diagnosis criteria, for data registering, bear into consideration the WHO recommendations for epidemiological studies [15]. Thus, for the crown assessment the DMFT Index (average of Decayed, Missing and Filled Teeth) were used. For the root status assessment as well as for the identification of root decay lesions, it was applied the Root Caries Index (RCI). This index was used in order to quantify the prevalence of surfaces with root caries, which was obtained by multiplying by 100 the quotient between the sum of the number of decayed root surfaces, with the number of filled root surfaces, over the sum of the decayed root surfaces with that of the filled root surfaces, as well as of the exposed and sound root surfaces. The Root Caries per Individual Index (RCIi) was calculated afterwards by adapting the formula for the RCI calculation, the number of surfaces being accounted per individual. Later, the RCIi was categorized into $<20 \%$ and $\geq 20 \%$ based on the 25th percentile of the observed distribution for the variable. 


\section{Data analyses}

Counts and proportions were reported for categorical variables, and 95\% confidence intervals (95\% CI) were calculated, using the Wald or Exact method, for prevalence of oral health conditions. Proportions were compared using the chi squared test. The kappa of Kohen coefficient was used to analyse the statistical agreement between observations collected twice by the first author, as well as with a calibrated external examiner. Quantitative data were described as average values and their respective standard deviation, or as median values and corresponding 25th and 75th centiles for nonnormally distributed variables. The comparisons between two or more than two groups were performed using the non-parametric tests $\mathrm{U}$ of Mann-Whitney and of Kruskal-Wallis, respectively, as the presupposition concerning normal distribution (Kolmogorov-Smirnov test) was not verified. Multivariable logistic regression was performed using the Wald backward stepwise estimate method $(\mathrm{p}=0.05$ for variable inclusion and $\mathrm{p}=0.20$ for variable exclusion) in order to estimate variables associated with RCIi $\geq 20 \%$ outcome. The statistical analysis procedures were performed using IBM(C SPSS @ Statistics vs. 19.0 (SPSS Inc., Chicago, IL, USA). Values of $\mathrm{p}<0.05$ were considered statistically significant.

\section{RESULTS}

\section{Socio-demographic sample characterization}

A total of 372 individuals from both genders, were assessed, representing $35.6 \%$ of the resident population in 22 visited nursing homes. This sample was composed of 260 women (69.9\%) and 112 men (30.1\%). The youngest individual was 60 years old and the oldest was 101, the average age being of 78.8 years. The biggest group representation, $41.9 \%$, is observed on ages ranging between 76 and 84 years old (Table I).
Table I - Age distribution of the participants from the sample (all and according to gender) and indication of the most relevant statistics (counts, percentage, average and standard deviation (stdev), median (25th and 75th percentiles), minimum and maximum)

\begin{tabular}{|c|c|c|c|c|c|c|}
\hline Age & n & $\%$ & $\begin{array}{l}\text { Average } \\
\text { ( } \pm \text { stdev) }\end{array}$ & $\begin{array}{c}\text { Median } \\
\text { (P25-P75) }\end{array}$ & Min-Max & $\mathbf{p}$ \\
\hline $60-65$ years & 43 & 11.6 & & & & \\
\hline $66-75$ years & 75 & 20.2 & & & & \\
\hline $76-84$ years & 156 & 41.9 & & & & \\
\hline$\geq 85$ years & 98 & 26.3 & & & & \\
\hline All & 372 & 100 & $78.8( \pm 9.1)$ & $80(73-85)$ & 60-101 & \\
\hline Gender $F$ & 260 & 69.9 & $79.3( \pm 8.8)$ & $81(74-85)$ & 60-101 & \multirow{2}{*}{0.125} \\
\hline All $\quad M$ & 112 & 30.1 & $77.7( \pm 9.7)$ & $79(71-84)$ & 60-98 & \\
\hline
\end{tabular}

In this sample $30.4 \%$ had not attended school and were illiterate and the majority, $55.8 \%$, had attended school for only a few years, in a maximum of 6 years. Only $4.9 \%$ of the observed had higher education. In the sample, 81.7\% (304) of the individuals was considered independent in relation with the aspects concerning their daily oral hygiene and 18.3\% (68) claimed needing assistance. The latter presented an average age of 80.5 years, slightly superior to 78.5 years, the average age of the independent individuals, difference that was proved to be insufficient in order to find significant differences as to what concerns the age of the two groups (MannWhitney-U test, $\mathrm{p}=0.161$ ).

\section{Oral health conditions}

The individual's characteristics in relation with the type of edentulism presented and the sort of denture used to compensate the tooth loss, in the upper jaw, as well as in the mandible, showed that 115 (30.9\%) of the assessed elderly were completely edentulous and only $2(0.5 \%)$ had all their teeth (Table II). 
Table II - Distribution of the sample participants according to their type of edentulism

\begin{tabular}{|c|c|c|c|}
\hline $\begin{array}{l}\text { Edentulism } \\
\text { situation }\end{array}$ & $\mathbf{n}$ & $\%$ & $95 \%$ Cl for $\%$ \\
\hline Has all the teeth & 2 & $0.5 \%$ & $0 \%-1.2 \%$ \\
\hline Total edentulous & 115 & $30.9 \%$ & $26.2 \%-35.6 \%$ \\
\hline $\begin{array}{l}\text { Partially } \\
\text { edentulous }\end{array}$ & 255 & $68.6 \%$ & $63.9 \%-73.3 \%$ \\
\hline All & 372 & $100 \%$ & \\
\hline
\end{tabular}

The biggest percentage of elderly were partially edentulous and most of them, 35.5\% [95\% CI: $30.6 \%-40.4 \%$ ] on the upper jaw and $40.6 \%$ [95\% CI: $35.6 \%$ - 45.5\%] on the lower jaw did not use any sort of denture whatsoever in order to compensate edentulism. There were 23 (6.2\%) [95\% CI: 3.7\% - 8.5\%] elders completely edentulous using dentures on the upper jaw, but not on the lower jaw, whereas $70(18.8 \%)$, [95\% CI: $14.8 \%-22.8 \%$ ], presented dentures on both arches.

From the 257 who presented, at least, one tooth in their mouths, 100 (38.9\%) claimed they did not brush their teeth on a daily basis and only $85(33.1 \%)$ said they had the habit of brushing two or more times a day. Females were the ones who brushed their teeth daily and for a bigger number of times (37\% female vs. $26.1 \%$ male). The number of daily tooth brushing was found to be influenced by the degree of Independence / Dependence expressed by the individuals, that is, an association between these two variables was registered (chi-square test, $\mathrm{p}=0.013$ ), showing that independent individuals brushed their teeth daily more times.

\section{Dental caries profile}

As to what concerns the number of teeth present in the mouth, 315 (84.9\%) of the elderly from the sample had less than 20 teeth, and the average number of teeth present in the mouth, per elder was of 8.9 ( \pm 8.7). The average value of the DMFT was 25.6, which leads to the conclusion that $50 \%$ of the elder observed showed a DMFT up to 28 and only $2(0.5 \%)$ of the individuals presented a DMFT of zero. The average percentage of decayed teeth is 7.1\% [95\%CI: 4.5\%-9.7\%], the one concerning tooth loss is $87.0 \%$ [95\%CI:
83.6\%-90.4\%] and the related with filled teeth is $4.7 \%$ [95\%CI: $2.6 \%-6.9 \%$ ]. In average, each elderly (Table III) presented 1.7 ( \pm 2.3 ) decayed teeth (DT) and of $0.9( \pm 2.1)$ for filled teeth (FT), although there were elders who present up to 14 filled teeth. There were $49.6 \%$ of elders with decayed teeth in their mouth. The percentage of those who had, at least, one missing tooth was of $99.5 \%$, with a average of 22.9 ( \pm 8.9) missing teeth (MT), while that of those who presented, at least, one restoration was of $28.0 \%$. One should also consider that $50.0 \%$ did not present any decayed tooth whatsoever, yet $50.0 \%$ of the elder presented a minimum of 25 missing teeth.

Table III - Decayed, missing and filled components of the DMFT index $(n=371)$ with indication to the most relevant statistics (average, standard deviation (stdev), median ( $25^{\text {th }}$ and $75^{\text {th }}$ percentiles), and minimum and maximum) as well as the calculation of the $95 \%$ confidence interval for its mean value

\begin{tabular}{|ccccc|}
\hline DMFT & $\begin{array}{c}\text { Average } \\
( \pm \text { stdev })\end{array}$ & $\begin{array}{c}\text { 95\%Cl for the } \\
\text { mean }\end{array}$ & $\begin{array}{c}\text { Median } \\
(\mathbf{P 2 5}-\mathbf{P 7 5})\end{array}$ & Min-Max \\
\hline Decayed & $1.8( \pm 2.3)$ & $1.6-2.0$ & $0(0-2.5)$ & $0-14$ \\
\hline Missing & $22.9( \pm 8.9)$ & $22-23.8$ & $25(16-32)$ & $0-32$ \\
\hline Filled & $0.9( \pm 2.1)$ & $0.7-1.1$ & $0(0-1)$ & $0-14$ \\
\hline
\end{tabular}

There were found no significant differences on DMFT by gender (Mann-Whitney-U test, $\mathrm{p}$ $>$ 0.05). Notwithstanding, as to what age is concerned, it can be concluded that there are significant differences in DMFT when related with the age (Kruskal-Wallis test, $\mathrm{p}<0.001$ ). As expected, age influences the index values, increasing it significantly. As it was observed on the oral hygiene habits, the degree of independence also influences the DMFT index values, allowing to present a lower DMFT index for those who are independent (median of $27 \mathrm{vs.}$ 32 for dependent, $\mathrm{p}=0,003$ ), as well as elderly with higher education present significantly lower DMFT values (median of 21.5 vs. 30 for no schooling, $\mathrm{p}<0.001$ ).

The RCI found was $40.6 \%$, of which $39.5 \%$ for females and a $42.2 \%$ for males. The RCIi (Root Caries Index per individual) allows to verify that in this assessment, 33 individuals were found with a value of $100 \%$, whereas 38 of the 240 
elderly who complied with the presuppositions for the tooth root decay assessment (Table IV), did not present any tooth root decay. This outcome reveals the existence of only $15.8 \%$ of the sample with teeth without tooth root decay and $10.2 \%$ of the overall sample. Individuals with tooth root decay, that is, those who presented exposed and decayed roots, represented 54.3\% of assessed people in the study. However, while evaluating the individuals with some teeth for root assessment, it was observed that $78.6 \%$ showed tooth root decay, which represents the prevalence of root caries in the individuals with teeth [95\%CI: 74.4\%-82.8\%]. The average number of root caries per individual assessed was of 3.4 ( \pm 3.6 ), varying between zero and 24 root caries.

In relation with gender, the RCIi values reveal that, in average, men present $44.3 \%( \pm$ $30.4 \%$ ) of tooth root decay and women $39.4 \%$ $( \pm 31.2 \%$ ), both genders being able to achieve values of $100 \%$, yet no significant RCIi differences were found by gender (Mann Whitney-U test, $\mathrm{p}>0.05)$. Individuals on the age range of $60-65$ years old presented an average RCIi of $30.3 \%$ ( \pm $22.6 \%$ ) and individuals with 85 years old or older presented an average RCli of $48.1 \%$ ( $\pm 32.7 \%$ ). The apparent growing tendency of the average RCIi for the age groups was confirmed, significant differences being able to be detected on the RCIi by age group (Kruskal-Wallis test, $\mathrm{p}<0.05$ ).

Table IV - Indication of the number of participants with tooth root decay (with $R D$ ), without tooth root decay (without RD), without exposed roots for assessment (without ER), with exposed roots for assessment (with ER) and participants totally edentulous (sample of 372)

\begin{tabular}{|c|ccc|}
\hline Tooth root decay & $\mathbf{n}$ & $\%$ & $95 \% \mathbf{C I}$ \\
\hline Individuals with RD & 202 & $54.3 \%$ & $49.2 \%-59.3 \%$ \\
\hline $\begin{array}{c}\text { Individuals } \\
\text { without RD }\end{array}$ & 38 & $10.2 \%$ & $7.5 \%-13.7 \%$ \\
\hline Individuals with ER & 240 & $64.5 \%$ & $59.5 \%-69.2 \%$ \\
\hline $\begin{array}{c}\text { Individuals without ER } \\
\text { Individuals totally eden- } \\
\text { tulous }\end{array}$ & 17 & $4.6 \%$ & $2.8 \%-7.2 \%$ \\
\hline
\end{tabular}

The variables age (years), gender, using a removable denture and number of daily tooth brushings were included in a logistic regression model. This model allowed to understand that age and gender are not significantly associated with the RCI forecast equal or superior to $20.0 \%$ in institutionalized elder partially edentulous (the initial categorization of the RCIi with up to $20.0 \%$ and equal or superior to $20.0 \%$ ). It was also found that the RCIi $\geq 20.0 \%$ in institutionalized elder partially edentulous was significant and independently associated with using a removable denture, as well as with the daily tooth brushing ( $\mathrm{p}<0.05)$. This model showed that institutionalized elder partially edentulous and using a metal removable partial dentures had a 5.3 fold probability increase of presenting a RCli $\geq 20.0 \%$, comparing with elders in other situations (did not include acrylic removable partial dentures ) $(\mathrm{OR}=5.348 ; \mathrm{p}=$ 0.030; 95\%CI: 1.176-24.329) (Table V).

Table V - Predictors of RCli equal or superior to $20 \%$ for partially edentulous institutionalized elderly, identified through multivariable* logistic regression $(n=237)$. The model correctly foresees $72.6 \%$ of the cases

\begin{tabular}{|c|ccc|c|}
\hline Variable & Category & p & OR & OR 95\%Cl \\
\hline \multirow{2}{*}{ Situation } & Other & 0.065 & 1 & \\
\cline { 2 - 5 } & $\begin{array}{c}\text { Partially edentulous acrylic } \\
\text { removable denture }\end{array}$ & 0.286 & 1.539 & $0.698-3.395$ \\
\hline & $\begin{array}{c}\text { Partially edentulous metal } \\
\text { removable denture }\end{array}$ & 0.030 & 5.348 & $1.176-24.329$ \\
\hline $\begin{array}{c}\text { Daily tooth } \\
\text { brushing }\end{array}$ & Brushes ( $\geq 1$ times) & 0.002 & 1 & \\
\hline & Does not brush (0 times) & 2.802 & $1.445-5.433$ \\
\hline & Constant & 0.018 & 1.589 & \\
\hline
\end{tabular}

* Variables included in the regression model: age (years), gender, use of removable denture, daily tooth brushing. Adjusted model: -2 Log likelihood $=263.7 ; \mathrm{R}_{\text {cox \& Snell }}=0.060$; $\mathrm{R}^{2}{ }_{\text {Nagelkerke }}=0.087$. Cl (confidence interval); OR (odds ratio)

\section{DISCUSSION}

The importance of studying the dental caries profile in a population is based upon either the assessment of the treatment's general effects to which elderly people were subjected throughout their lives, or of the repercussions caused by the absence of dental medical treatment, a situation which is characteristic in these populations. 
Nevertheless, in these advanced age population, during the dental caries profile assessment, one must not forget that combined with this condition, are the physiological changes of the oral cavity that came together with age and the repercussions deriving from them, which develop adequate conditions for the expression of the above mentioned pathology, directly influencing their assessment.

Based upon the dimensions of elderly residing in nursing homes in the Oporto District, Northern Portugal, the minimum sample dimension needed for the study was estimated and 372 elders were assessed, representing $35.6 \%$ of the residing population in the 22 nursing homes visited. The nursing home's selection was performed randomly (probabilistic). This way, 260 women (69.9\%) were assessed, as well as 112 men (30.1\%). An similar characterization, as to what concerns gender and age average, was found by other authors in studies performed on elderly populations from several countries in the world [11,12,14,16,17,19-25].

Within the assessed sample, $30.4 \%$ had not attended school and were illiterate whatsoever and as for the majority of elders, $55.8 \%$, had attended school for a maximum period of 6 years. Only $4.9 \%$ of the observed elders claimed having higher education studies, the lower levels of literacy being associated with females. The issue of education was registered by other authors in identical assessment studies, in which the results were similar $[2,17,22,26]$. The assessment of this parameter is directly related with the fact that one often associates elderly education or literacy level to their oral health condition, namely as to the importance he might bestow upon maintaining a healthy mouth. In Brazil, a study performed in an elderly population concludes that studying less than 4 years is an indicator in relation to non-perception of the oral health's interference in social relationships[27], a fact which comes together with the claimed statements. However, in the present study, the degree of education did not relate itself with the number of times elderly brushed their teeth (chi-square test, $\mathrm{p}=0.065$ ). Yet, one can claim that the education levels,
"Illiterate" and "Basic education" presented a higher percentage of elders whom did not brush their teeth, as opposed to the "Medium/ Average" and "Superior/Higher" levels. The knowledge concerning the need to take care of the mouth and teeth does not depend upon an increased academic education. These individuals might have a bigger probability of accessing information as to the need of tooth brushing, as well as to the implications of a poor hygiene, but, in reality, the habit is related with principles provided with upbringing and personal hygiene cares. Other authors did not found a significant statistic relation between the educational degree and the oral hygiene of elderly nursing home's residents, also mentioning that the elders who were assessed all claimed to perform the oral hygiene tasks on their own, without any help [28]. Amongst the elders who participated in the study, $81.7 \%$ (304) was considered independent in regard of their daily oral hygiene and $18.3 \%$ (68) claimed needing assistance.

Of the $38.9 \%$ who did not brush their teeth, $71.1 \%$ did not feel the need to do it, only $2.4 \%$ claimed not possessing the manual dexterity to do it and $6.0 \%$ claimed lack of assistance. The complementary means of oral hygiene were unknown for the majority of the observed elders, an aspect which is registered in other studies held in populations with the same characteristics $[28,29]$. Only $85(33.1 \%)$ declared to have the habit of brushing their teeth 2 or more times a day. Similar tooth brushing frequencies have been registered in other studies in populations with similar characteristics, with small variations, namely as to what concerns the way of assessing the tooth brushing frequency issue. All of them, nonetheless, concluding that their daily tooth brushing habits are similar [21,28].

\section{Dental Caries profile}

Little is known about the natural history of the presence of dental caries amongst older adults but, recently, some reports deriving from a series of big cohort studies allowed for a better understanding of the nature, as well as of the determinants of dental caries on elders. A 
systematic review on dental caries incidence was published, concluding that the elders are a risk group for active dental caries, the crown dental caries bearing the highest contribution for the disease. Enhancing the necessity for strategies with multiple prevention activities, many authors identify the factors which might contribute for the development of dental caries on elderly population: poor oral hygiene, the changes on both quality and quantity of saliva, the psychic and functional inabilities, as well as the socioeconomic factors $[12,25,30]$.

The elders tooth condition assessment, as to what concerns the past or present dental caries history aspects, in the present study, registered mean DMFT values of 25.6 ( \pm 7.3 ), it was found $37.4 \%$ of individuals with an index of 32 and only $0.5 \%$ of individuals with DMFT of zero. Identical values can be found in similar studies of populations with the same characteristics $[12,21,24,25,27,31]$.

The prevalence of decayed teeth was $7.1 \%$, filled $4.7 \%$ and $86.8 \%$ were missing, bearing into consideration that the DMFT values in this population are directly influenced by the $\mathrm{M}$ component. This, diverges the values in an exponential way in populations with these characteristics, for the percentage of elders who presented, at least, one missing tooth was of 99.5\% and those who presented, at least, one restoration was $28.0 \%$. On each elder person, it was registered, in average, $1.8( \pm 2.3)$ decayed teeth(DT), 22.9 ( \pm 8.9) missing teeth(MT) and 0.9 ( \pm 2.1 ) filled teeth(FT), different values from those published in other studies[12,21,31] and as to what concerns the individual assessment of the DMFT components. This fact can be justified by the absence of dental medical care of the Portuguese population for many years; the individuals assessed in this study still belonging to the generations during which the Portuguese oral health public service was totally disregarded. For this reason, the sample values on filled teeth were lower to those on the referred studies. The DMFT index was found to be associated with the elders' dependency for the oral hygiene's tasks issue, with the dependent elderly presenting higher values. This is also true for literacy, which is equally registered as being associated with the DMFT values, since higher education degrees present lower DMFT values.

The number of teeth present on the mouth of the elders from the sample was assessed so it could be related to their health condition. It was found $84.9 \%$ of the elderly with less than 20 teeth, that is, only $56(15.1 \%)$ of the individuals of the sample had 20 or more teeth. In average, one found an average of 8.9 teeth present on the mouth of the individuals, which are different values from that registered by other authors, in studies performed on elderly populations $[11,19,21,24]$. The presence of a specific number of teeth with dental caries has been an aspect studied by many authors and has been associated with several predisposing factors, including age, gender, education and oral hygiene, sociodemographic as well as economic conditions and dental services access perception [32,35]. Other studies relate the number of teeth present in elderly people's mouths with difficulties in eating, which might be harmful in terms of nutritional condition, particularly obesity, as well as general health [33]. Some times the number of teeth is independently associated with mortality, thus meaning that an improvement on oral health might have a positive impact over general health, being able to delay the decrease on quality of life or even delay death [34].

Since the 90's that several publications have been associating tooth root decay with age, gender, the fluoridation of drinkable water, race, specific microorganisms, the presence of crown caries and the number of remaining teeth. The tooth root decay diagnosis is problematic, since it is not clinically easy to distinguish the area of the carious lesion. Besides, in the case of elders, lesions extend to the proximal and, sometimes, to the sub-gingival surfaces. The clinical approach of such lesions may, also, be complex, presenting some specificities' such as the suited caries removal, as well as control during the restoration procedures, which may lead to many relapses. This sort of dental caries has been a growing clinical problem due to the increase of elderly 
dentate population during the last two decades.

Assessing root surfaces for determining the presence of tooth root decay was performed in the present study, in a direct way, without the proper hygienization so that the assessment would be considered as not having modifying factors. What it means is that no accumulated Materia Alba and/or plaque on the surfaces were removed, which, in some situations, might have influenced the correct diagnosis. Nevertheless, one must not consider this aspect as having been exclusive to the present study. In the studies published and performed with institutionalized elders, and in similar assessment conditions, this factor as well as the difficulty in confirming the presence of proximal root caries, only detected through radio-diagnosis, certainly influenced the values obtained and are never mentioned. The $\mathrm{RCI}$ is one of the most widely used index for tooth root decay in the populations yet, the criteria differ from study to study. A series of studies have been reporting throughout the years the high prevalence of root caries on elders $[35,36]$. The average RCIi value, for the 240 individuals with teeth in whom was considered possible to evaluate the presence of tooth root decay was of $43.8 \%$. It was verified that the tooth root decay presents a prevalence of $78.6 \%$ between elder people with teeth. The mean number of root caries was of $3.4( \pm 3.6)$ per elderly, varying between 0 and 24 cavities. Lower prevalence values of tooth root decay were registered in studies performed in other countries, in populations with the same characteristics $[35,37]$. Similar values of tooth root decay prevalence can, however, be found in other works of identical characteristics $[6,36]$.

The mean RCIi value was found higher for the males $(44.3 \%)$ than for the females $(39.4 \%)$, without significant statistical differences (MannWhitney-U test, $\mathrm{p}>0.05$ ). For the age group of 85 years old or older, the RCIi registered the highest value (48.1\%) and the 60-65 years group registered the lowest value (30.3\%), yet significant differences were only detected between the oldest and the youngest groups and between the oldest and the age group of 7684 years old (Mann-Whitney-U test, $\mathrm{p}=0.010$ and $\mathrm{p}=0.047$ respectively). Through these results, one can conclude that age, the number of existing teeth and the number of root surfaces with recessions, are conditions which may lead to higher RCI, the former having been, on the Kularatne \& Ekanayake study, considered as being predicting factors of the presence of tooth root decay [19]. Other factor presents higher RCI values on their assessments done in studies with institutionalized elder people [6], cases in which the samples presented similar characteristics to those of the population in this study.

The oral hygiene assessment, through the daily tooth brushing frequency, demonstrated that the group of elders who did not brush showed significant differences in the RCIi in relation with the group of elders who brushed once and with the group who brushed more than once (Mann-Whitney-U test, $\mathrm{p}<0.001$ and $\mathrm{p}=$ 0.040 , respectively). However, tooth brushing once or more than once a day does not present differences on the RCIi. It can be concluded that the number of decayed roots is susceptible of being smaller on individuals who referred brushing their teeth more frequently, considering bad oral hygiene a potential risk factor for root caries. This conclusion is also supported by other authors [38,39].

The maintenance of oral hygiene in the institutionalized elderly is an aspect that should be integrated into daily tasks, being a part of the caregivers' protocols when taking care of the personal hygiene of each elderly. These tasks have to be particularly addressed to the elderly while considering situations of decreased manual dexterity or visual acuity, that is, the overall ability to properly perform personal oral hygiene. Dental professionals or even oral hygienists should contribute to the writing of the institutions' oral hygiene protocol.

A logistic multivariable regression model was built, in order to identify variables that would foresee the presence of a high root caries (stipulated as RCIi equal or superior to $20 \%$ ), on the individuals with teeth of the sample. The obtained results showed that age 
and gender are not significantly associated to RCIi $\geq 20 \%$. Nevertheless, the value of RCIi $\geq$ $20 \%$ is significant and independently associated with the use of individual removable partial denture as well as with daily tooth brushing, the fact remaining that an institutionalized elderly, partially edentulous and using a metal removable partial denture presented a 5.3 fold increased probability of having a RCIi $\geq 20 \%$ when compared to non-dentures' users. This condition was also assessed in the Nevalainen study, that refers the presence of any kind of removable denture as being associated with the increase of tooth root decay [40]. In a opposite way, other referred authors conclude that the use of removable partial denture does not contribute for the increase of root caries [9]. The number of daily tooth brushings in the model shows that elders who do not brush have a 2.8 fold increased probability of having a RCIi $\geq 20 \%$, in relation with elders who brush their teeth $(p=0.002)$. The application of the logistic regression model in our study, in relation with the RCIi, is justified by the significant associations established between the dependent variable considered and each one of the predicting factors which we have associated.

The high prevalence of dental caries in this institutionalized elderly population in the Northern Portugal is compatible with the widespread elderly population's ignorance regarding the importance of good oral hygiene and its contribution to the oral disease profile. The difficult access to oral health care by this population also contributes to the situation identified in this study.

Knowledge and effort should unite, in the sense of converging towards an oral health promotion, throughout an individual's entire life. The former covers several dimensions: individual, professional, institutional and political as well as organizational, with the purpose of living and aging in a healthy manner, according to the concept of active aging from the World Health Organization.

\section{CONCLUSION}

The prevalence of dental caries in this elder institutionalized population of Northern Portugal is high, mostly due to bad oral hygiene habits associated to the use of metal removable partial dentures. Institutionalized elderly need protocols tailored to their oral health needs and integrated efforts in the institutions are needed to effectively answer the demands related to ageing deterioration with decline of physiological functions.

\section{Acknowledgements}

The research team would like to thank the "PASOP" mobile unit (ambulatory project of public and oral health) of the University Fernando Pessoa for the space where clinical observations with dental equipment and good lighting conditions were possible.

The last author also acknowledges the support of FP-ENAS.

\section{REFERENCES}

1. Fallin MD, Matteini A. Genetic epidemiology in aging research. J Gerontol ABiol Sci Med Sci 2009; 64:47-60. doi: 101093/gerona/gln021

2. Farooqui T,Farooqui AA. Aging: An important factor for the pathogenesis of neurodegenerative diseases. Mech Ageing Dev 2009; 130: 203-215. doi:10.1016/j.mad.2008.11.006

3. Petersen PE, Yamamoto T. Improving the oral health of older people: the approach of the WHO Global Oral Health Programme, 2005. Community Dent Oral Epidemiol 2005;33:81-92. doi:10.1111/j.1600-0528.2004.00219.x

4. Selwitz RH, Ismail Al, Pitts NB. Dental caries. Lancet 2007;369:51-59. doi:101016/S0140-6736(07)60031-2

5. Petersen PE. The World Oral Health Report 2003: continuous improvement of oral health in the 21st century - the approach of the WHO Global Oral Health Programme. Community Dent Oral Epidemiol 2003;31(Suppl. 1):3-24. doi:10.1046/j.2003.com122.x

6. Steele JG, Sheiham A, Marcenes W, Fay N, Walls AW. Clinical and behavioural risk indicators for root caries in older people. Gerodontology 2001; 18: 95-101. doi:10.1111/j.1741-2358.2001.00095.x

7. Fejerskov 0, Baelum V, Ostergaard ES. Root caries in Scandinavia in the 1980's and future trends to be expected in dental caries experience in adults. Adv DentRes 1993; 7:4-14. doi:10.1177/08959374930070010501

8. Fure S. Five-year incidence of caries, salivary and microbial conditions in 60-,70-and 80-year-old Swedish individuals. Caries Res 1998; 32: 166-174. doi:10.1159/000016449

9. Imazato S, lkebe K, Nokubi T, Ebisu S, Walls AW. Prevalence of root caries ina selected population of older adults in Japan. J Oral Rehabil 2006; 33: 137-143. doi:10.1111/j.1365-2842.2006.01547.x 
10. Henriksen BM, Ambjornsen E, Laake K, Axell T.Prevalence of teeth and dentures among elderly in Norway receiving social care. Acta Odontol Scand 2003; 61: 184-191. doi:10.1080/00016350310003701

11. Iglesias Corchero AM, Garcia Cepeda JR. Oral health in people over 64 years of age, institutionalized in Centres for the Aged in the Vigo Health District Spain, 2005. Med Oral Patol Oral Cir Bucal 2008; 3: E523-528.

12. Baciero R, Gandarias FJG, Perez LM. Periodontal Community Study; Pathology of Hard Dental Tissues: Study of Caries; Stomatological Prostheses. In: Oral Health in the Elderly in Spain. Ediciones Eguia Sl, 1998: 47-166.

13. Kularatne S, Ekanayake L. Root surface caries in older individuals from Sri Lanka.Caries Res 2007;41:252-256. doi:101159/000101913

14. Ćatović $A$, Jerolimov V, Catic $A$. Tooth loss and the condition of the prosthodontic appliances in a group of elderly home residents. J Oral Rehabil 2000;27:199-204. doi:10.1046/.1365-2842.2000.00521.x

15. WHO. Oral health surveys: basic methods. 4th ed. World Health Organization, Geneva, Switzerland, 1997:41.

16. Triantos D. Intra-oral findings and general health conditions among institutionalized and non-institutionalized elderly in Greece. J Oral Pathol Med 2005;34:577-582. doi:10.1111/.j.1600-0714.2005.00356.x

17. Mollaoglu N, Alpar R. The effect of dental profile on daily functions of the elderly. Clin Oral Investig 2005;9: 137-140. doi:10.1007/s00784-005-0307-6

18. Saunders R, Friedman B. Oral health conditions of community-dwelling cognitively intact elderly persons with disabilities. Gerodontology 2007;24: 67-76. doi:10.1111/.j.1741-2358.2007.00160.x

19. Tramini P,Montal S, Valcarcel J. Tooth loss and associated factors in longterm institutionalised elderly patients. Gerodontology 2007;24: 196-203. doi:10.1111/.j.1741-2358.2007.00183.x

20. Ikebe K, Nokubi T,Ettinger RL. Utilization of dental health services by community-dwelling older adults in Japan who attended a weekly educational programme. Gerodontology 2002; 19: 115-122. doi:10.1111/.17412358.2002.00115.x

21. Unluer, S, Gokalp S, Dogan BG. Oral health status of the elderly in a residential home in Turkey. Gerodontology 2007;24:22-29. doi:10.1111/.17412358.2007.00136.x

22. Musacchio E, Perissinotto E, Binotto P etal. Tooth loss in the elderly and its association with nutritional status, socio-economic and lifestyle factors. Acta Odontol Scand 2007; 65: 78-86. doi:10.1080/00016350601058069

23. Ferro R, Besostri A, Strohmenger L etal. Oral health problems and needs in nursing home residents in Northern Italy. Community Dent Health 2008; 25:231-6.

24. Simunkovic SK, Boras W, Panduric J, Zilic IA. Oral health among institutionalised elderly in Zagreb, Croatia. Gerodontology 2005;22: 238-241. doi:10.1111/1.1741-2358.2005.00086.x

25. Henriksen BM,Ambjornsen E, Axell T.Dental caries among the elderly in Norway. Acta Odontol Scand 2004; 62: 75-81. doi:10.1080/00016350310008580
26. Mesas AE, de Andrade SM, Cabrera MA. Factors associated with negative self-perception of oral health among elderly people in a Brazilian community. Gerodontology 2008;25:49-56. doi:10.1111/.1.1741-2358.2007.00196.x

27. Nunes $\mathrm{Cl}$, Abegg C. Factors associated with oral health perception in older Brazilians. Gerodontology 2008;25:42-48. doi:10.1111/.1741-2358.2007.00163.x

28. Akar GC, Ergul S. The oral hygiene and denture status among residential home residents. Clin Oral Investig 2008; 12:61-65. doi:10.1007/s00784-007-0136-x

29. Siukosaari P,Ainamo A. Level of education and incidence of caries in the elderly: a 5-year follow-up study. Gerodontology 2005; 22: 130-136. doi:10.1111/.j.1741-2358.2005.00070.x

30. Ferreira RC, de Magalhaes CS, Moreira AN. Tooth loss, denture wearing and associated factors among an elderly institutionalised Brazilian population. Gerodontology 2008;25: 168-178. doi:10.1111/j.1741-2358.2008.00214.x

31. Gluhak C, ArnetzI GV, Kirmeier R, Jakse N, ArnetzI G. Oral status among seniors in nine nursing homes in Styria, Austria. Gerodontology 2010;27:47-52. doi:10.1111/j.1741-2358.2009.00281.x

32. Vysniauskaite S, Kammona N, Vehkalahti MM. Number of teeth in relation to oral health behaviour in dentate elderly patients in Lithuania. Gerodontology 2005;22: 44-51. doi:10.1111/.1741-2358.2004.00040.x

33. Hilgert JB, Hugo FN, de Sousa MdaL, Bozzetti MC. Oral status and its association with obesity in Southern Brazilian older people. Gerodontology 2009;26:46-52. doi:10.1111/.1741-2358.2008.00226.x

34. McGrath C,Bedi R. Can dentures improve the quality of life of those who have experienced considerable tooth loss? J Dent 2001;29:243-246. doi:10.1016/ s0300-5712(00)00063-4

35. Locker D, Slade GD, Leake JL. Prevalence of and factors associated with root decay in older adults in Canada. J Dent Res 1989;68: 768-772. doi:10.1177/002 20345890680050301

36. Warren JJ, Cowen HJ, Watkins CM, Hand JS. Dental caries prevalence and dental care utilization among the very old. J Am Dent Assoc 2000; 131: 15711579. doi:10.14219/jada.archive.2000.0086

37. Fure S. Ten-year cross-sectional and incidence study of coronal and root caries and some related factors in elderly Swedish individuals. Gerodontology 2004; 21: 130-40. D0l:10.1111/.1741-2358.2004.00025.x

38. DePaola PF,Soparkar PM, Kent RL Jr. Methodological issues relative to the quantification of root surface caries. Gerodontology 1989b; 8:3-8. doi:10.1111/.1.141-2358.1989.tb00395.x

39. DePaola PF, Soparkar PM, KentRL Jr.Clinical profiles of individuals with and without root surface caries. Gerodontology 1989a; 8:9-15. do::10.1111/.1741-2358.1989.tb00396.x

40. Nevalainen MJ,Narhi TO, Ainamo A. A5-year follow-up study on the prosthetic rehabilitation of the elderly in Helsinki, Finland. J Oral Rehabil 2004; 31:647-652 doi:10.1111/j.1365-2842.2004.01280.x

\section{M.C. Manso}

(Corresponding address)

Faculty of Health Sciences, University Fernando Pessoa, Rua Carlos da

Maia, 296, 4200-150 Porto, Portugal

Phone: +351-225071300, Fax: +351-225508269

Date submitted: 2019 Nov 10

Accept submission: 2020 Jan 22 